\title{
Cardiac lipoma in the interventricular septum: a case report
}

\author{
Dan Li ${ }^{1}$, Weitie Wang ${ }^{1}$, Zhicheng Zhu' ${ }^{1}$ Yuefeng Wang ${ }^{2}$, Rihao Xu ${ }^{1}$ and Kexiang Liu ${ }^{1 *}$
}

\begin{abstract}
Primary cardiac tumors are rare. The cardiac lipoma cases have been sparsely reported. We report a case of interventricular septal lipoma complicated with mild tricuspid regurgitation in a 65-year-old Chinese male. The patient presented with shortness of breath after exertion. His diagnosis was made with echocardiogram, cardiac magnetic resonance imaging, cardiac computed tomography and post-operative histopathology. The patient underwent tumor resection and postoperative recovery was uneventful. He was asymptomatic with no recurrence at 8-month follow-up.
\end{abstract}

Keywords: Cardiac tumors, Lipoma, Cardiac surgery, Pathology

\section{Background}

Primary cardiac tumors are uncommon. It has been reported that approximately $75 \%$ of the primary cardiac tumors are benign [1]. Cardiac lipomas account for $8.4 \%$ of the primary tumors of the heart and pericardium [2]. Cardiac lipomas are benign nonmyxomatous neoplasms of the heart, they can occur at any age with an equal frequency in both genders [3] and in almost any locations in the heart. They are not easily clinically diagnosed, and differ in regard to clinical manifestations, locations, morphology, sizes and radiological findings [4]. They are uncommon and usually found in the right atrium and left ventricle. Since cardiac lipomas are wellencapsulated tumors and typically composed of mature fat cells, they are true neoplasms, unlike hypertrophic lipomatosis, in which there is deposition of nonencapsulated mature and fetal adipose tissue [5]. A cardiac tumor in the IVS occurs in only $2 \%$ of cases [6]. Therefore, the combination of a rare tumor (lipoma) in a rare location (IVS) is particularly unusual [7], it is to say, lipoma in the IVS is very rare. Albers was the first to report cardiac lipoma in 1856, and about 60 cases had been reported until 1995 [8]. We present a rare case of lipoma located in the interventricular septum (IVS). The tumor was successfully resected surgically.

\footnotetext{
* Correspondence: kxliu64@hotmail.com

${ }^{1}$ Department of Cardiovascular Surgery, 2nd Hospital of Bethune, Jilin University, Changchun, Jilin, China

Full list of author information is available at the end of the article
}

\section{Case presentation}

A 65-year-old Chinese male experienced chest congestion and shortness of breath after exertion for 11 years, but he had ignored them. He presented with worsening dyspnea and increasing fatigue for the past 3 months. His blood pressure was $133 / 72 \mathrm{mmHg}$ and his heart rate was 110 beats per min. Heart auscultation revealed grade II ejection systolic murmur at the left parasternal border. Electrocardiogram showed normal sinus rhythm. Transthoracic echocardiogram (TTE) showed a homogeneous parenchymal mass of $27 \times 12 \mathrm{~mm}$ in size with peripheral hyperechogenicity. The mass located in the mid-basal portion of IVS, anterior to the right coronary sinus. There was mild tricuspid regurgitation (TR) without annular dilatation and cusp prolapse on TTE. Cardiac magnetic resonance imaging (MRI) showed a round-like signal, measuring $36 \times 20 \mathrm{~mm}$, in the upper portion of IVS, anterior to the right coronary sinus of aorta. The images of tissue characterization suggested that the mass was consisted of adipose tissue (Fig. 1). Cardiac computed tomography $(\mathrm{CT})$ scan with intravenous contrast confirmed the existence of a round-like hypodense mass $(-117 \mathrm{Hu})$, measuring $37 \times 21 \mathrm{~mm}$ in its largest diameter, superior to the IVS and anterior to the right coronary sinus of aorta (Fig. 2).

The traditional surgical treatment has been performed. A standard median longitudinal sternotomy was carried out. Cardiopulmonary bypass $(\mathrm{CPB})$ was routinely applied, and myocardial protection through the aortic 


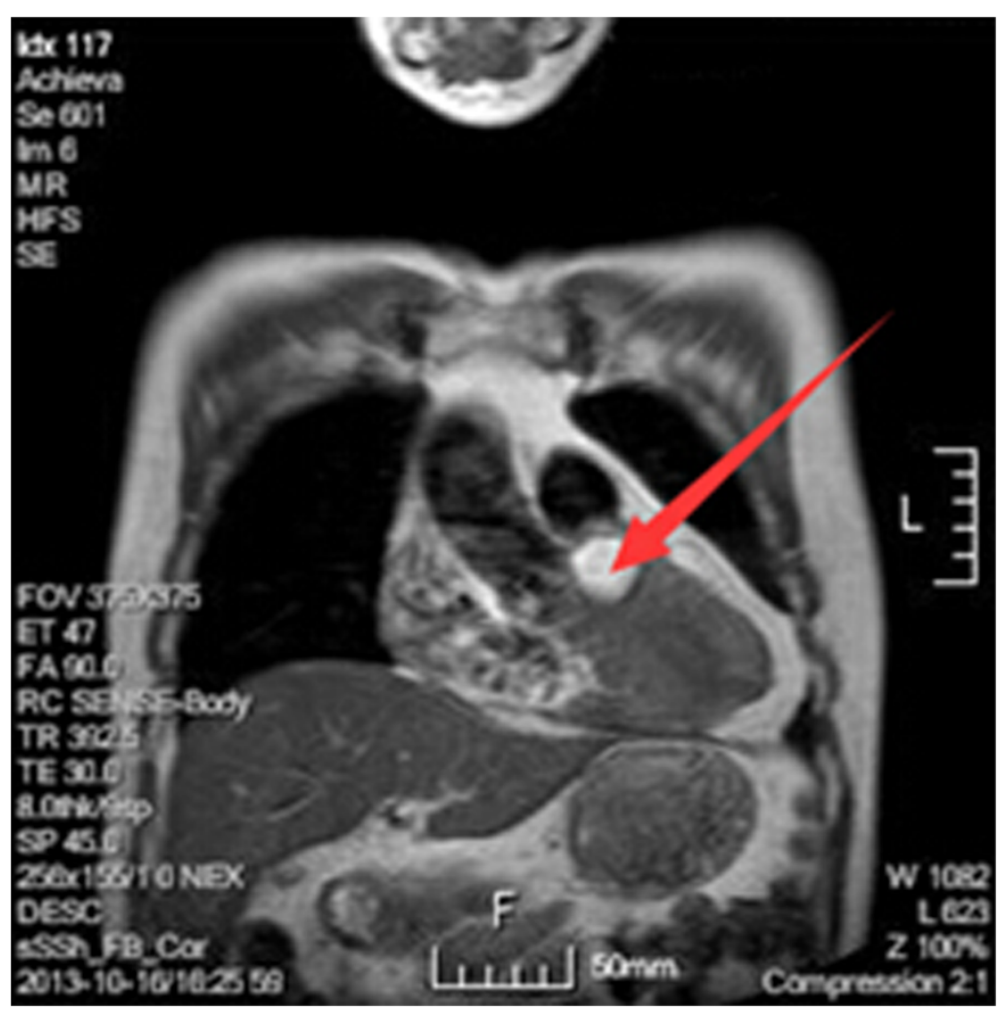

Fig. 1 Cardiac MRI showed a round-like signal, measuring $36 \times 20 \mathrm{~mm}$, in the upper portion of IVS, anterior to the right coronary sinus of aorta

root infusion of cold cardioplegic solution and topical hypothermia of the heart. Antegrade cardioplegic arrest was achieved after application of an aortic cross-clamp. After longitudinal incision of right atrium and the main pulmonary artery, a yellowish neoplasm was found embedded in the upper portion of IVS beneath the pulmonary valve, projecting into the right ventricular outflow tract. The muscular septum was incised longitudinally and the tumor was excised en bloc from the IVS. The muscular septum and the right ventriculotomy were re-approximated with running 4-0 prolene sutures. Postoperative pathology reported lipoma (Fig. 3), measuring $40 \times 30 \times 20 \mathrm{~mm}$, encapsulated and composed of mature adipose tissue. The patient recovered well without any complications. He was discharged on the postoperative day 13. His pre-operative symptoms resolved and no further medication treatment is needed. The patient was doing well in his 8 months post operative follow up appointment.

\section{Conclusions}

The clinical manifestations of cardiac lipoma depend on the location of the tumor, and may vary from valvular dysfunction to obstruction of a cardiac chamber, impeding the filling and emptying processes [9]. Symptoms may include heart failure, arrhythmia and syncope. Tumors of the right atrium, interatrial septum, and right ventricle can predispose to arrhythmias [10]. Türkoglu $\mathrm{H}$ and his colleagues [11] reported a case of a 24-year-old woman who presented with palpitations and was found to have a lipoma attached to the left side of the IVS. Our patient felt chest congestion and shortness of breath after physical activity for a long time and worsening dyspnea and increasing fatigue whose lipoma located in the upper portion of IVS projecting into the right ventricular outflow tract. The increasing size of the tumor caused underfilling of the right ventricle with rapid deterioration of symptoms. The location and size of the tumor may contribute to the patient's symptoms. The cardiac lipoma can be diagnosed by echocardiogram, $\mathrm{CT}$ and MRI. Echocardiogram is useful to diagnose both benign and malignant tumors. The use of CT scan and MRI are facilitated to the diagnosis of the lipomas and exactly predict the intramyocardial extent and the relationship to other cardiac structures [12]. MRI is particularly useful because it allows the characterization of the tissue [13]. In our case, a mass in the heart was initially detected with transthoracic echocardiogram. CT scan and MRI were further applied to characterize the mass. Post operative pathology confirmed the pre-operative diagnosis of lipoma. So we think that echocardiogram, CT and MRI are necessary to the diagnosis of the cardiac tumor.

Because of potential lethality, theoretically, all cardiac tumors should be indicated for surgery, independing 


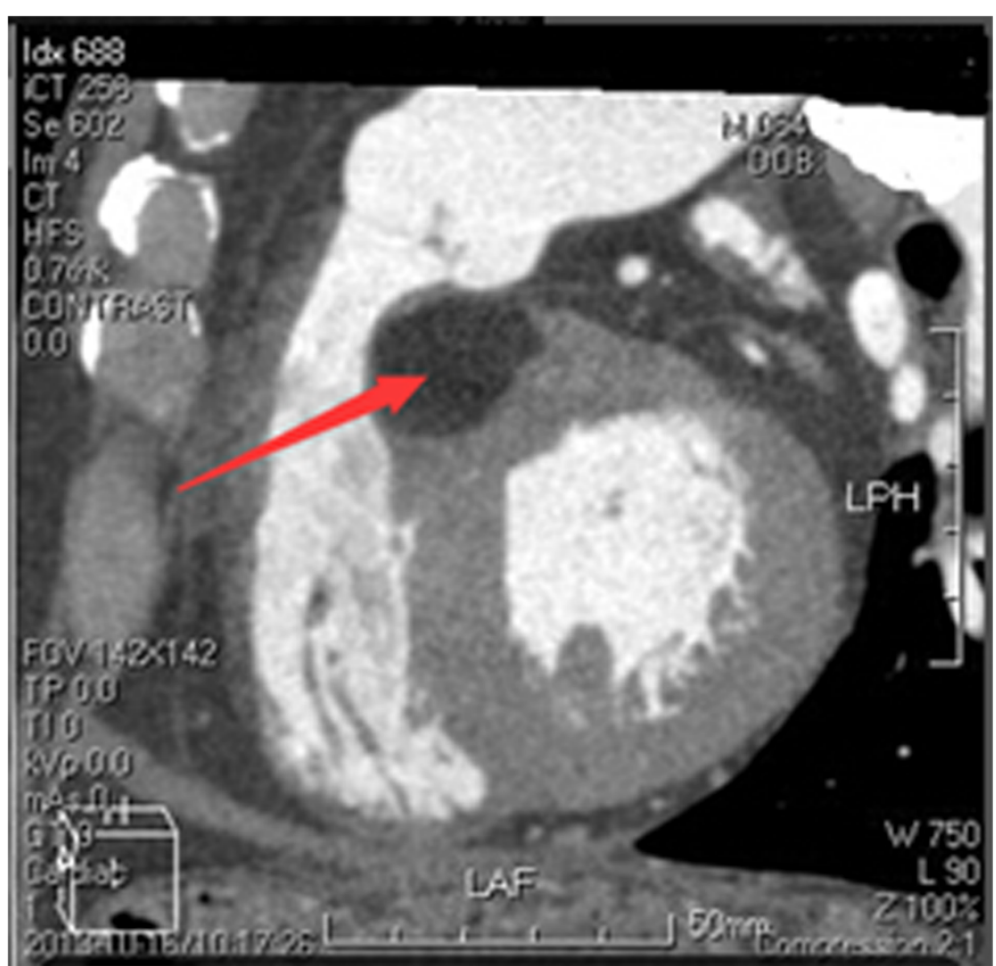

Fig. 2 Cardiac CT images with contrast confirmed the existence of a round-like hypodense mass $(-117 \mathrm{Hu})$, measuring $37 \times 21 \mathrm{~mm}$ in its largest diameter, superior to the IVS and anterior to the right coronary sinus of aorta.

from symptomatology. If there are no contraindications, surgical resection is the treatment of choice for all patients with cardiac neoplasms. The approaches to resect the tumor depends on tumor sizes and locations. In this case, the patient was symptomatic and deteriorated progressively. We recommended surgical treatment and advise this patient to reexamination twice a year after successful treatment.

\section{Consent}

Written informed consent was obtained from the patient for publication of this Case report and any accompanying
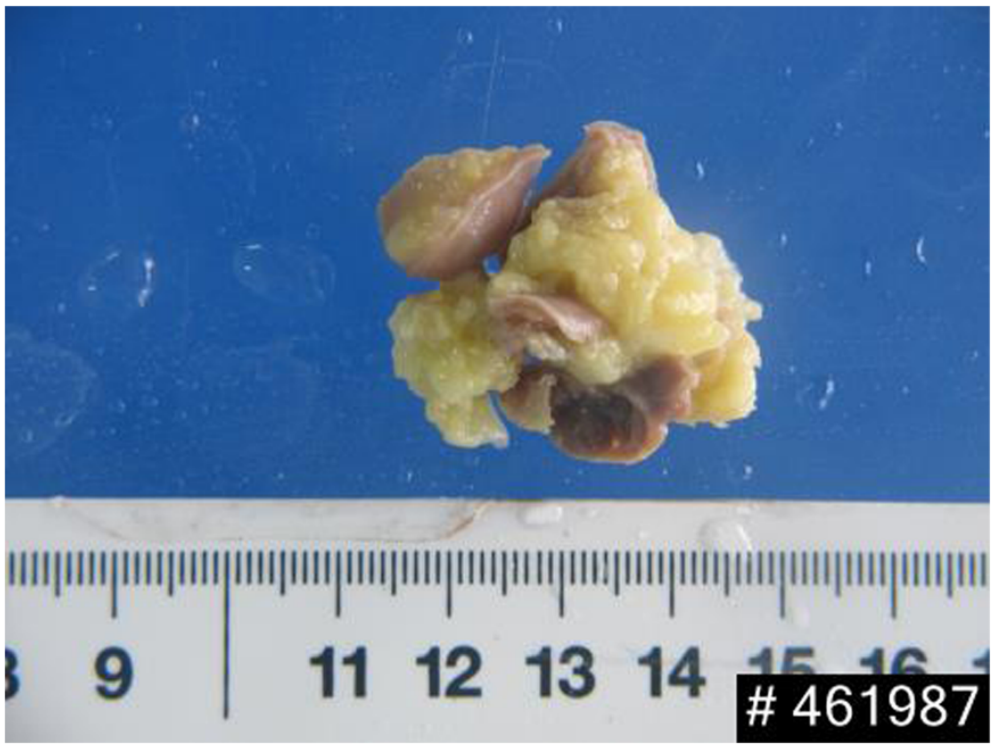

Fig. 3 Intraoperative photograph of the resected lipoma 
images. A copy of the written consent is available for review by the Editor-in-Chief of this journal.

\section{Competing interests}

The authors declare that they have no competing interests.

\section{Authors' contributions}

All authors participated in the design of the case report and coordination and helped to draft the manuscript. All authors read and approved the final manuscript.

\section{Acknowledgement}

We acknowledge support by JiLin University (JLU) within the funding program Open Access Publishing

\section{Author details}

${ }^{1}$ Department of Cardiovascular Surgery, 2nd Hospital of Bethune, Jilin University, Changchun, Jilin, China. ²Department of Cardiovascular Surgery, Daqing Oilfield General Hospital, Daqing, Heilongjiang, China.

Received: 7 December 2014 Accepted: 1 May 2015

Published online: 09 May 2015

\section{References}

1. Heath D. Pathology of cardiac tumors. Am J Cardiol. 1968;21:315-27.

2. Colucci WS, Schoen FJ, Braunwald E. Primary tumors of the heart. In: Braunwald E, editor. Heart disease:a textbook of cardiovascular medicine. 2nd ed. Philadelphia: WB Ssunders; 1997. p. 1464-77.

3. Gulmez O, Pehlivanoglu S, Turkoz R, Demiralay E, Gumus B. Lipoma of the right atrium. J Clin Ultrasound. 2009;37:185-8.

4. Araoz PA, Eklund HE, Welch TJ, Breen JF. CT and MR imaging of primary cardiac malignancies. Radiographics. 1999;19:1421-34.

5. Alcocer JJ, Katz WE, Hattler BG. Surgical treatment of lipomatous hypertrophy of the interatrial septum. Ann Thorac Surg. 1998;65(6):1784-6.

6. Fernandes F, Soufen HN, lanni BM, Arteaga E, Ramires FJ, Mady C. Primary neoplasms of the heart. Clinical and histological presentation of 50 cases. Arq Bras Cardiol. 2001;76(3):231-7.

7. Nishi H, Mitsuno M, Ryomoto M, Hao H, Hirota S, Miyamoto Y. Giant cardiac lipoma in the ventricular septum involving the tricuspid valve. Ann Thorac Surg. 2009;88(4):1337-9.

8. Mullen JC, Schipper SA, Sett SS, Trusler GA. Right atrial lipoma. Ann Thorac Surg. 1995;59(5):1239-41.

9. Khalili A, Ghaffari S, Jodati A, Shokoohi B, Pourafkari L. Giant right atrial lipoma mimicking tamponade. Asian Cardiovasc Thorac Ann. 2013;0(0):1-3.

10. Matta R, Neelakandhan KS, Sandhyamani S. Right atrial lipoma. Case report. J Cardiovasc Surg. 1996;37:165-8.

11. Türkoglu H, Alkan T, Okçün B, Akçevin A, Paker T, Ersoy C, et al. Symptomatic lipoma in the interventricular septum. ASAIO J. 2006;52:e35-6.

12. Lang-Lazdunski L, Oroudjii M, Pansard Y, Vissuzaine C, Hvass V. Successful resection of giant intrapericardial lipoma. Ann Thorac Surg. 1994;58:238-41.

13. Salanitri JC, Pereles FS. Cardiac lipoma and lipomatous hypertrophy of the interatrial septum: cardiac magnetic resonance imaging findings. J Comput Assist Tomogr. 2004;28:852-6.

\section{Submit your next manuscript to BioMed Central and take full advantage of:}

- Convenient online submission

- Thorough peer review

- No space constraints or color figure charges

- Immediate publication on acceptance

- Inclusion in PubMed, CAS, Scopus and Google Scholar

- Research which is freely available for redistribution 